\title{
Online Interactivity - A Shift towards E-textbook-based Medical Education
}

\author{
Aldona Dutkiewicz ${ }^{1}$, Barbara Kołodziejczak ${ }^{2}$, Piotr Leszczyński ${ }^{3}$, \\ Iwona Mokwa-Tarnowska ${ }^{4}$, Paweł Topol ${ }^{5}$, Barbara Kupczyk ${ }^{6}$, \\ Idzi Siatkowski ${ }^{7}$
}

${ }^{1}$ Faculty of Mathematics and Computer Science, Adam Mickiewicz University in Poznan, Poland

2 Department of Computer Science and Statistics, Poznan University of Medical Sciences, Poland

3 Department of Nursing and Emergency Medicine, University of Natural Sciences and Humanities, Siedlce, Poland

${ }^{4}$ Language Centre, Gdańsk University of Technology, Poland

5 Faculty of Educational Studies, Adam Mickiewicz University in Poznan, Poland

6 Department of Pathophysiology, Poznan University of Medical Sciences, Poland

7 Faculty of Agriculture and Bioengineering, University of Life Sciences in Poznan, Poland

\begin{abstract}
Textbooks have played the leading role in academic education for centuries and their form has evolved, adapting to the needs of students, teachers and technological possibilities. Advances in technology have caused educators to look for new sources of knowledge development, which students could use inside and outside the classroom. Today's sophisticated learning tools range from virtual environments to interactive multimedia resources, which can be called e-textbooks. Different types of new educational materials that go beyond printed books are now used to support the academic curriculum, with the most interesting ones exemplified in this article to show their value in medical and life sciences education. Certain interesting attempts by Polish publishers at applying technology to support both self-paced and tutor-paced student learning in the medical profession and related areas are presented. The data was collected through a review of literature, discussions with e-learning specialists and medical students, as well as an analysis of examples of good practices. The article also discusses the results of a countrywide survey on the use of e-textbooks to enhance medical education. The research investigates the targeted academic staff's attitudes towards the use of e-textbooks, the limitations of their implementation, and the character of e-resources currently used by Polish higher education medical institutions.
\end{abstract}




\section{Introduction}

Technological advances have opened up new possibilities of enriching text-based content with interactive multimedia, i.e., simulations, animations, video or audio. This has resulted in educators trying to find more engaging ways to increase knowledge than those possible in a traditional classroom. Online resources with various functionalities, which enable embedding multi-purpose activities, are gradually replacing paper-based textbooks in academic education (Bates et al., 2012; Seid-Karbasi et al., 2017). Internet and mobile devices, which are becoming all-pervasive in the modern academic curriculum, permit the learning process to be individualized and tailored to meet the academic needs of different students (RenKurc et al., 2013; Sandholzer et al., 2014).

An analysis of the implementation of e-materials to support academic education provided by Polish higher education institutions is a considerable challenge due to their relatively large number, amounting to about 400, according to Ministry of Science and Higher Education's estimation from 2018 (http://wybierzstudia.nauka.gov.pl/pages/about/index). Moreover, universities do not always reveal information about their education systems, and those which have their own e-learning systems do not allow guest access.

The authors conducted research on the implementation of online interactive multimedia materials in medical education. The data was collected through a review of literature (Ditmyer et al., 2012; Sandholzer et al., 2014), discussions with e-learning specialists and medical students, as well as an analysis of examples of good practices (Harvey et al., 2016). An online survey into the types of educational materials to support students of medicine and health sciences targeted Polish medical institutions of higher education.

\section{E-textbooks - Definition and Features}

New technological possibilities allow changing forms of education by making them more engaging and interactive. They enable educators and students to use varied means, delivery modes and methods. The major aim of incorporating innovative solutions is to increase the effectiveness and attractiveness of the educational process, which is now subject to extensive transformations in Poland. The most popular and widespread teaching and learning resources were and still are paper textbooks. However, tech- 
nological advances and more student-centred pedagogical paradigms have caused them to undergo various changes, ranging, e.g., from information presentation to study modes.

Research into practice and a review of academic publications and textbooks, supported by an in-depth analysis of the materials available on various educational platforms (mainly at the academic level), make it possible to formulate the thesis that no unambiguous definition of the concept of an 'e-textbook' exists (Leszczyński et al., 2017; Ren-Kurc et al., 2013; Walat, 2013). Moreover, there are no basic indications or instructions that publishers should follow.

Whereas e-textbooks are agreed to be electronic resources, their referents can vary. For some educators, they can be multimedia textbooks. Others can mistakenly understand them to be equivalent to e-books and online resources in PDF format or digital copies of the printed version, which are available on an electronic screen. However, the diversity of their functionalities shows that they are new types of educational materials.

E-textbooks are not traditional publications transferred to digital media and read on the screen - they are e-resources that make full use of the possibilities of the virtual environment. In the authors' understanding, etextbooks should be defined as interactive multimedia resources used for educational purposes. They are created to enable students of any age to learn with the use of all available media channels (Szulc, 2018), and interactivity is achieved through the affordances of their tools.

Today's students grew up in an environment filled with ubiquitous modern technology and are accustomed to using language abbreviations and sending short messages (Rickes, 2016). In the first place, they pay attention to graphics and use the Internet extensively (Berezovskaya \& Shipunova, 2015; Mynbayeva et al., 2018). This determines the way of learning to a large extent, as well as the ability to develop knowledge and skills, and results in them using multimedia and online tools to aid whatever task they are involved in.

Furthermore, the impact on the senses of hearing, sight and touch is important in the learning process (Rockinson-Szapkiw et al., 2013). The preferred channel of perception of information divides learners into those who learn better visually, through listening or kinaesthetically. Thus, the most important issue is to create appropriate materials supporting the teaching process, enriched with a set of purposefully selected solutions structured around an online multimedia environment, and tailored to individual learning styles. 
All things considered, the characteristic features of the model etextbook are as follows:

- a well-defined knowledge structure in terms of a balanced development of cognitive skills (such as information collection, remembering, integration, analysis, and practical use) and appropriate proportions between text and multimedia content and/or interactive activities;

- online multimedia (films, animations, simulations, virtual labs, etc.);

- interactivity (elements enabling active work, e.g., interactive graphic exercises, interactive quizzes, experiments returning interactive results);

- convenient navigation and an embedded search system;

- non-linear reading paths tailored to the difficulty level;

- integration with Internet resources to enhance the learning experience.

To summarize, an e-textbook is an integrated collection of multimedia content that enables the student to interact with it, and allows them to find information not only inside, but also on other websites thematically related to the subject matter (Lorens, 2013).

\section{E-materials for Medical Education}

As mentioned above, a widely-accepted term for an electronic interactive textbook that contains online multimedia resources with embedded activities has not yet been coined. Different types of new educational materials that go beyond printable text-based resources are now available to teach university students. The following examples show attempts at applying technology to support both self-paced and tutor-paced student learning in the medical profession and related areas.

Sloodle is an acronym for Simulation Linked Object Oriented Dynamic Learning Environment. In other words, it is a free and open source system that supports learning and teaching via a web-based learning management system (Moodle-like LMS), which is integrated with a 3D serious virtual world, e.g. Second Life (SL) (Sloodle, 2012). Students' work happens in two ways: (1) they use the LMS content (e-materials) and perform tasks; both the content and their assignments are also available from SL, and (2) students perform activities in SL and the results of their work are automatically transferred to the LMS platform. In this way the student can make use of materials, including e-books, in both environments.

Jaime Alamo Serrano gives a very comprehensive description of the Sloodle system, modules and tools in her co-authored book (Garcia \& Serrano, 2009). She discusses communication in Sloodle, delivery of learning 
material, content creation, organization of meetings and events, collaboration and gaming, as well as assessment, feedback and tracking Sloodle. A comprehensive presentation of Sloodle-based medical courses and tools is also available in Radovic et al., (2015). The scope of this article does not allow to present them fully.

Sloodle has been used by many universities and colleges. For example, School of Medicine at Imperial College London has used Sloodle in their medical courses. In addition to implementing SL and Sloodle in education, they have also researched them. The aim of their study was to investigate pedagogical opportunities offered by the integration of a web-based virtual learning environment and the virtual world of SL and/or OpenSim. The project lasted a whole year, from July 2010 to June 2011. Its outcomes confirmed that integration of Sloodle and SL "has proven to be a robust system in terms of reliability, security and performance" (Imperial College of Science, Technology and Medicine, London, 2017).

As far as medical training in SL is concerned, though not supported by Sloodle, very interesting developments have also taken place at Heartstone Community Hospital (HCH, 2018) - the new expansion of the NBBC Medical Care System; State of the Art Adult, Paediatric \& Maternity Care. Their practice is focused on realistic 3D roleplay for Maternity \& Medical needs.

Elsevier, an international multimedia publishing house and a leading global provider of scientific and health information, creates interactive learning systems for students in the form of innovative series of 3D anatomical atlases. It also uses advanced gaming technology to view, learn and teach anatomy. InteractElsevier has two types of environments, i.e. an interactive website in the form of a $3 \mathrm{D}$ atlas (online) and virtual reality (stereoscopic).

The following tools are available in InteractElsevier:

- Imaging (Particular images can be correlated to interactive 3D models),

- Anatomy builder (The whole body or its parts can be constructed by region and by body system),

- Virtual Dissection (Structures can be removed to make complex relationships in anatomy clearer and more understandable),

- Labelling (Every structure of the body can be labelled with fully interactive, dynamic labels),

- Netter Plates (An Atlas can be compared to your 3D structure),

- Layers/Peeling (Space can be organized using features such as transparency, peel, or hide to understand the spatial relationship in a more precise way). 
InteractElsevier's interactive 3D tools have an intuitive flexible interface, correlated CTs and MRIs, a searchable terminology base, exploratory exercises, quizzes, and real-time interactivity. Being visually stimulating and the first truly interactive product of its kind, InteractElsevier is a highquality tool for students, lecturers and doctors.

All universities and colleges across the UK support their students with ebooks, i.e. the digital format of regular textbooks, usually in PDF or EPUB format. Their uptake is limited, but growing, and such initiatives as BiblioTech (Bibliotech, 2018) (Figures 1 and 2) and Jisc's free subscription eBooks for FE to all UK FE institutions (Jisc, 2018) are gaining popularity.
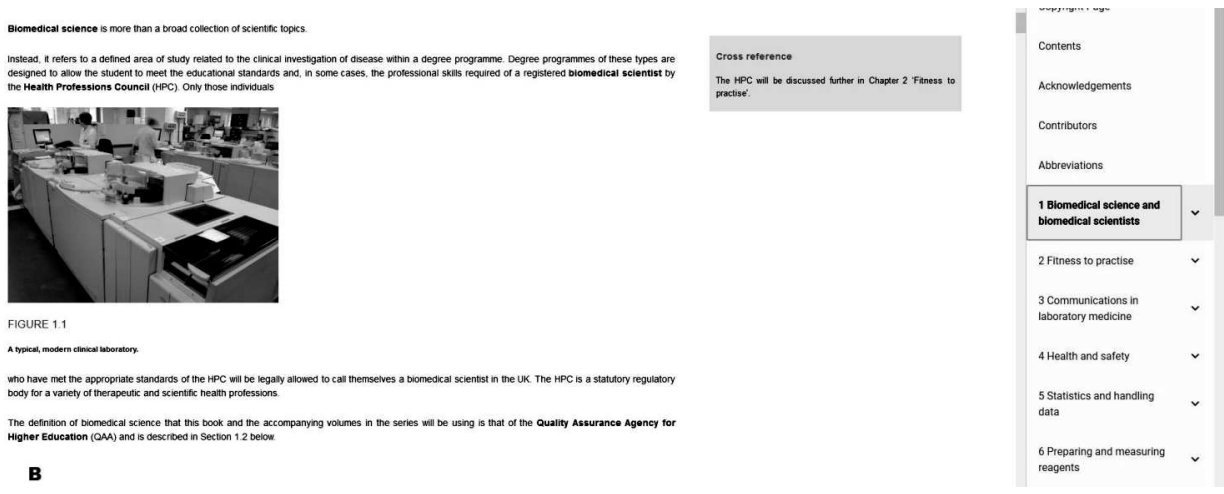

Figure 1. Non-interactive digital textbooks
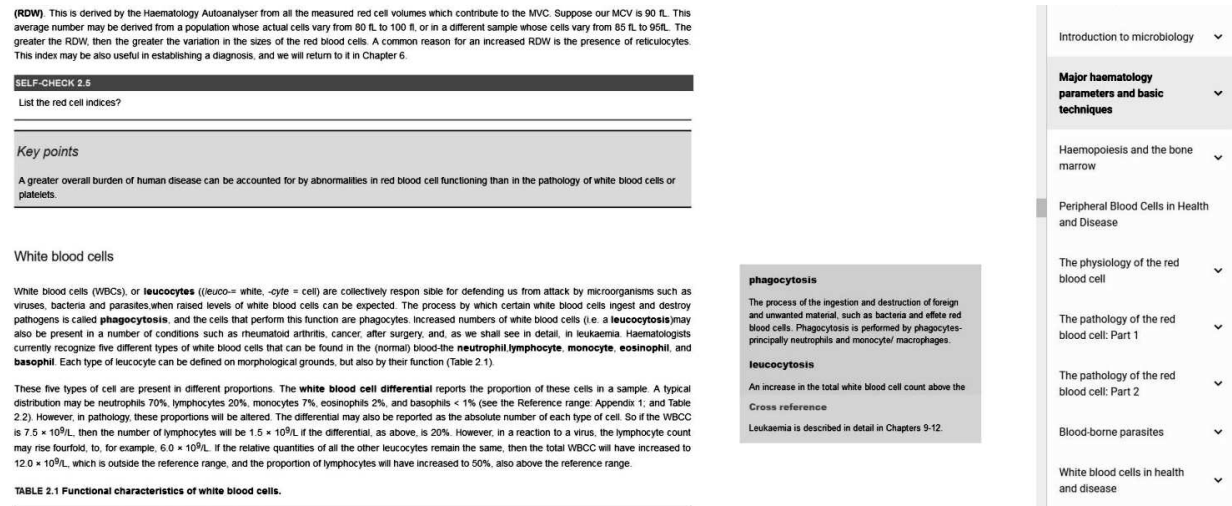

Figure 2. Digital textbook with links to related pages within the same resource

A number of UK-based publishers offer additional online components to support their textbooks, the most common format being online quizzes (Figure 3). Depending on the subject matter, however, they can also pro- 


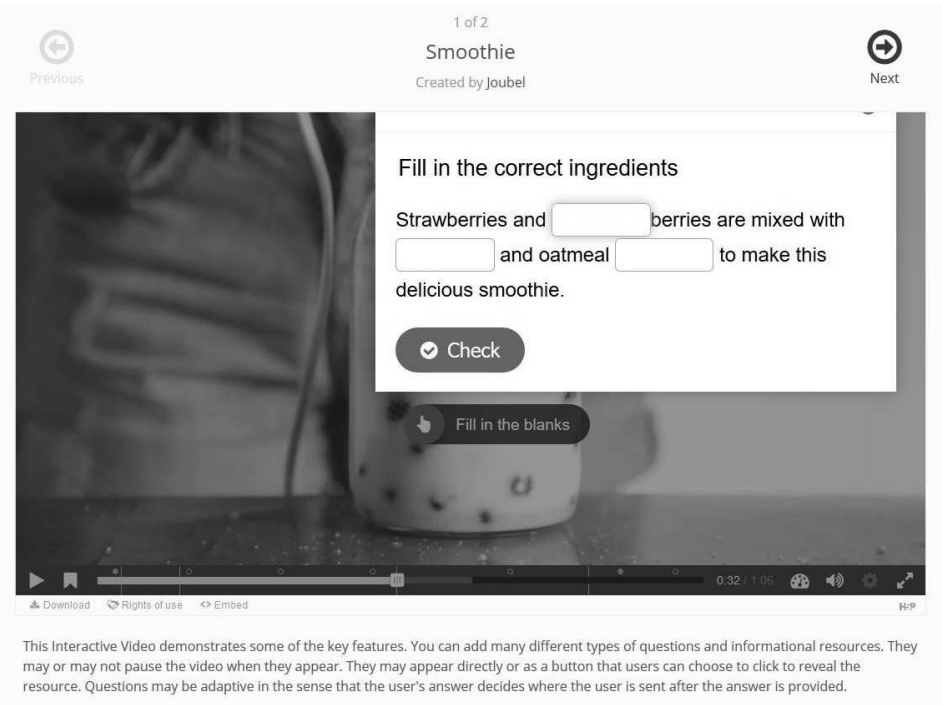

Figure 3. Resources with embedded quizzes or links to pages with quizzes

vide access to simulations and virtual lab activities. Moreover, there can be e-learning modules delivered as SCORM objects, or webpages with embedded activities, which UK-based educational institutions develop for their students. These, however, are not treated as distinctive online interactive textbooks.

One of the most advanced initiatives directed at American university students of Medicine and the English-speaking medical community across the world is the first interactive medical textbook for the iPad, iPhone and Mac, i.e. Ganong's Review of Medical Physiology. One of the most popular texts on human physiology, which was previously published as a paperbased resource, was released on the Inkling platform in 2011. It contains over 600 zoomable illustrations accompanied by two types of review questions. The touch-response-based modules and videos offer enhanced learning experiences.

In Poland, besides the aforementioned categories of online resources available in the UK, a new concept of online educational material is emerging, one which blurs the established distinction. Not yet adequately named, it emphasizes the interactivity that is embedded in text-and-picture-based content supplemented with animations and video. The best example is Prof Zbigniew Kąkol and Dr Jan Żukrowski's E-physics, which is an online interactive textbook with a variety of tasks included within each module (Kąkol \& Żukrowski, 2017) (Figure 4). With its multi-format interactivity, it is 


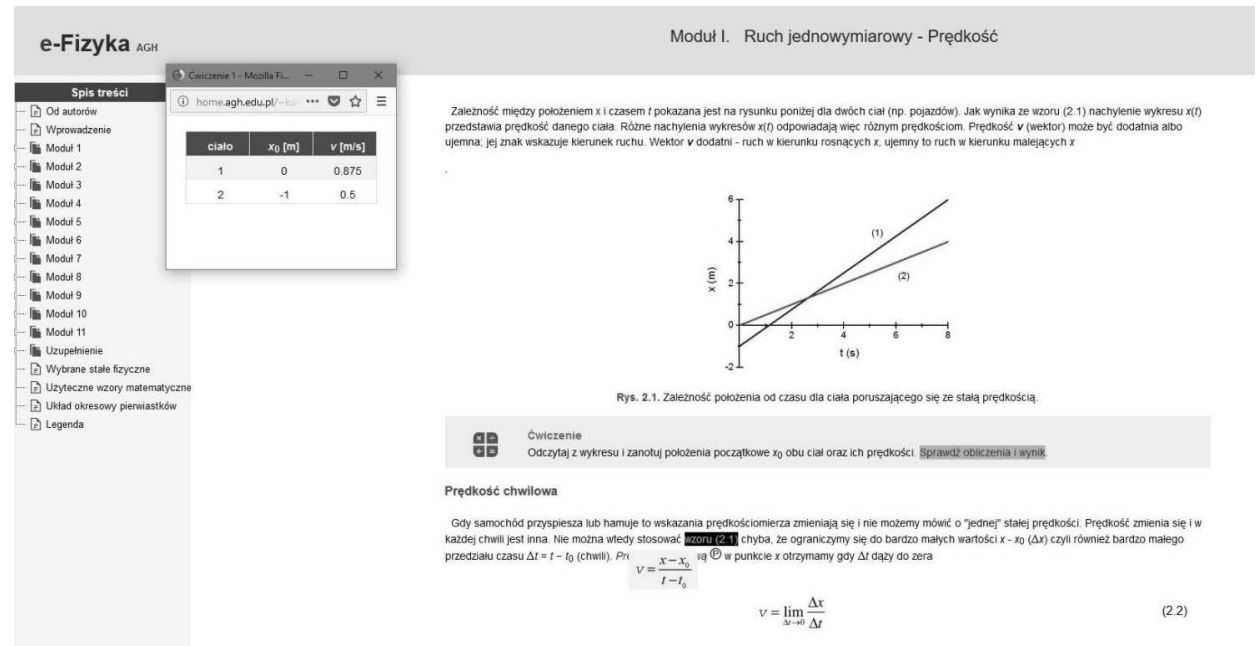

Figure 4. Online interactive textbook with a variety of tasks included on each page

a step forward when compared to such resources as the interactive atlas on the Inkling platform. This highly interactive resource can be used by students of Biomedical Engineering at various universities as it is free and the hardware requirements are not excessive.

To sum up, the section above discusses three aspects of e-materials in medical training rather than three examples of specific e-textbooks. The first one shows how the same e-materials can be used and shared in two different virtual environments: www and, e.g., Second Life. The second one presents how e-books may be integrated with 3D simulations. The third one gives examples of e-materials that are much more than simple PDF documents generated from word processor documents. All these aspects provide insight into the different ways in which an e-material can be used in education in Poland, and in medical education worldwide.

\section{E-resources from Polish Publishing Houses}

The concept of an e-textbook and the differences between a traditional, printed textbook and an e-textbook, which is an online resource with elements of interaction with the reader and multimedia, are unfamiliar to a number of university staff, especially those who are non-technically minded. Electronic versions of traditional textbooks in printable formats are often considered to be the most convenient sources of knowledge for 
university students. The lack of a financial support system and proper technical support effectively hampers the process of preparing multimedia and interactive e-textbooks.

An important and, as it turns out, difficult to implement factor, is access to a textbook via a web browser from any computer connected to the Internet. By definition, resources in the global network are open, therefore any access restrictions require unification of technologies and methods of preparation of such a resource. Moreover, different rules for editing internet publications and those intended for printing exist. In Poland, all the possible modes of publication are currently available, i.e.:

- traditional (i.e. the printed version of a textbook),

- access to the electronic version of a textbook (using a browser),

- access to the electronic version with printable option (possibility of printing fragments).

Commercial publishing firms are technologically prepared to publish etextbooks, i.e. they help edit them and provide the software environment. Technical editing is not free and the authors are required to deliver readymade components, e.g. multimedia, not intended for printing. Commercial versions of their e-textbooks purchased by universities are accessible through university libraries, and require user authorization. Publishing houses often run temporary access services (rentals). Fees that students have to pay can be considerable, especially if they need to rent several e-textbooks during the semester. For example, PZWL (State Medical Publishing) offers its clients subscription access to over 950 e-books, including over a hundred published by academic publishers. The free reader application myIbuk not only allows the users to read books online and offline, but it also provides the options of word or phrase search, creating notes, selecting fragments of pages, copying a bibliography or printing excerpts.

It should be noted that some publishing houses offer their resources, including e-magazines and e-books, under the open access license. Information on this subject can be found for example on the website of the Mossakowski Medical Research Centre, Polish Academy of Sciences (Open Access, 2018).

In some universities (e.g. in the Department of Pathophysiology of the Poznan University of Medical Sciences), multimedia courses and interactive tests are created for particular groups of students attending a specific course. These are resources and activities that are structured around the concept of an e-textbook, and which can be used to develop a model e-textbook in the future.

Universities of technology seem to encounter fewer difficulties in preparing e-textbooks, especially those related to topics concerning technology. 


\section{E-textbooks to Support Polish Medical Educational Institutions - Research}

Research into the use of e-textbooks and e-resources to enhance the academic educational process is a considerable challenge. There are only under our hundred colleges and universities in Poland (Ministry of Science and Higher Education, 2018), and e-learning is not widely offered by them (Hołowiecki, 2014).

Assessing the level of implementation of e-textbooks and e-resources in academic education, identifying the difficulties in this process, and examining the opinions of staff who use them are the first steps towards an increase in the number of web-based educational materials to support courses provided by Polish universities and colleges. The following research questions were addressed:

- What percentage of universities have their own e-textbooks or have started developing them?

- What did the process of creating them involve?

- What is the form and subject matter (courses/topics) of their etextbooks?

- What components do their e-textbooks consist of?

- How do university and college staff assess the usefulness of e-textbooks in the education process?

- What are the barriers to implementing an e-textbook at universities?

Materials and Methods. Pilot studies were conducted based on the authors' questionnaire available online. The questionnaire contained fourteen closed and semi-open questions, and four open questions. It was sent to forty medical higher education institutions, including nine medical universities. The quantitative research, whose results are presented in this paper, involved surveys carried out from March to June 2018. Responses were received from thirteen medical institutions $(\mathrm{n}=13)$, i.e., three universities and six higher vocational colleges and four educational units offering postgraduate courses or continuing education programmes in the field of medical and/or health sciences. The obtained data was subjected to a statistical analysis.

The data is presented as percentages or medians, interquartile ranges (lower quartile, upper quartile), minimum and maximum values, as appropriate. For a comparison of the two groups, the Mann-Whitney U test was applied. The nominal data was analysed with the Fisher-Freeman-Halton test. All the results were considered significant at $p<0.05$. Statistical anal- 
yses were performed with STATISTICA 12.0 PL (StatSoft Polska, Kraków, Poland) and StatXact 11.0 (Cytel Inc., Cambridge, MA, USA).

Results and Discussion. Only in five cases (38.5\%) did the examined universities have e-textbooks. Other institutions are in the process of creating them $(\mathrm{n}=5,38.5 \%)$ or do not have e-textbooks $(\mathrm{n}=3,23 \%)$. The respondents from the latter group completed the survey in accordance with their knowledge and expectations. Some of the institutions started using e-textbooks as early as in 2010, others in 2017. Out of the ten universities that had already implemented e-textbooks or were in the process of implementing them at the time of the study, only one declared both the purchase of educational materials and the IT system from a commercial company. The remaining ones created them themselves $(n=7)$ or commissioned their implementation $(\mathrm{n}=2)$. It is noteworthy that at the institutions where electronic textbooks were developed by their staff, the teams significantly differed in size. The number of teachers or authors of the content ranged from 2 to 20, and the number of engineering and technical staff ranged from 0 to 3 .

E-textbooks are most often meant for students of emergency medicine $(\mathrm{n}=8,62 \%)$, nursing $(\mathrm{n}=6,46 \%)$, medicine $(\mathrm{n}=4,31 \%)$, as well as public health, physiotherapy, electroradiology, speech therapy, biotechnology, cosmetology, and others. According to the authors, such a high percentage of e-textbooks used to train paramedics in Poland can be explained by their statutory possibility of professional improvement through online educational programmes (Leszczyński et al., 2017; Wejnarski et al., 2018). Subjects taught online or supported by online learning include basic, behavioural, and social sciences, as well as clinical and pre-clinical studies. The vast majority of respondents $(77 \%)$ regard e-textbooks as obligatory resources, and their course curricula are structured around them. Students obtain ECTS credits for completing such courses.

In the opinions of the examined respondents who use e-textbooks $(\mathrm{n}=5)$, online educational materials for medical majors should mainly include: a clear distinction between the knowledge components (100\%), multimedia content (100\%), interactive elements (100\%), an assessment of the understanding capacity (100\%), and the degree of information remembered $(100 \%)$, condensed version printing (100\%), and search by keywords (80\%). There were no statistically significant differences (all $p>0.05$ ) in the opinions provided by the respondents who have an experience in creating e-textbooks and those that lack it or are still in the process of developing such materials. 
The respondents are also in agreement on the factors that constitute a barrier to the creation of e-textbooks, which are as follows: lack of IT competencies, lack of appropriate remuneration for the authors of e-textbooks, and a time-consuming preparation process of this type of educational materials (Table 1 ).

Table 1. Assessment of barriers to creating e-textbooks by university staff

\begin{tabular}{|c|c|c|c|}
\hline $\begin{array}{l}\text { Question } 16 \text { : What is the } \\
\text { barrier to creating e-text- } \\
\text { books by your University } \\
\text { staff? }\end{array}$ & $\begin{array}{l}\text { The university has } \\
\text { e-textbook(s) for the } \\
\text { medical faculties } \\
\text { group } \mathrm{n}=5\end{array}$ & $\begin{array}{l}\text { The university does } \\
\text { not have any e-text- } \\
\text { books for medical } \\
\text { subjects or they are } \\
\text { in the preparation } \\
\text { group } \mathrm{n}=8\end{array}$ & p-value \\
\hline $\begin{array}{l}\text { The process of development } \\
\text { of an e-textbook requires } \\
\text { appropriate IT competencies }\end{array}$ & $2(40 \%)$ & $6(75 \%)$ & 0.293 \\
\hline $\begin{array}{l}\text { The process of development } \\
\text { of an e-textbook is too time- } \\
\text { consuming }\end{array}$ & $3(60 \%)$ & $6(75 \%)$ & 1 \\
\hline $\begin{array}{l}\text { No remuneration for devel- } \\
\text { oping an e-textbook }\end{array}$ & $4(80 \%)$ & $2(25 \%)$ & 0.103 \\
\hline No IT support & $2(40 \%)$ & $1(13 \%)$ & 0.511 \\
\hline $\begin{array}{l}\text { Lack of online pedagogy } \\
\text { support }\end{array}$ & $1(20 \%)$ & $0(0 \%)$ & 0.385 \\
\hline $\begin{array}{l}\text { Very good e-textbooks are } \\
\text { available }\end{array}$ & $1(20 \%)$ & $1(13 \%)$ & 1 \\
\hline
\end{tabular}

The respondents from the colleges and universities that use their own etextbooks assess highly their usefulness in medical education, although there were no statistically significant differences between the groups (Table 2).

The study has shown the need to increase the use of e-textbooks in order to enhance course curricula at medical institutions, reduce barriers to the implementation of such resources at universities and colleges, and develop a positive attitude of academic staff towards the use of electronic textbooks to support students majoring in medicine. A lack of feedback from other Polish medical institutions, which shows their unwillingness to provide information about their education process, has impacted the study. This is why, to obtain the full picture on a national scale, further research in this area is necessary. 
Table 2. Evaluation of the usability of e-textbooks on a scale from 1 to 10

\begin{tabular}{|l|c|c|c|}
\hline \multicolumn{1}{|c|}{ Question no. } & $\begin{array}{c}\text { The university has } \\
\text { e-textbook(s) for the } \\
\text { medical faculties } \\
\text { group } \mathrm{n}=5\end{array}$ & $\begin{array}{c}\text { The university does } \\
\text { not have any e-text- } \\
\text { books for medical } \\
\text { subjects or they are } \\
\text { in the preparation } \\
\text { group } \mathrm{n}=8\end{array}$ & p-value \\
\hline $\begin{array}{l}\text { Question 14. How do you } \\
\text { assess the usefulness of } \\
\text { e-textbooks for medical } \\
\text { courses at your university? }\end{array}$ & $\begin{array}{c}\text { Me }=10 \\
(5-10)\end{array}$ & $\begin{array}{c}\text { Me }=8 \\
(1-10)\end{array}$ & 0.244 \\
\hline $\begin{array}{l}\text { Question 15. How do you } \\
\text { assess the usefulness of e- } \\
\text { textbooks by other universi- } \\
\text { ties/publishing houses and } \\
\text { commercial publications } \\
\text { for students majoring in } \\
\text { medicine? }\end{array}$ & $\begin{array}{c}\text { Me }=7 \\
(5-9)\end{array}$ & $\begin{array}{c}\text { Me }=7 \\
(5-10)\end{array}$ & 0.936 \\
\hline
\end{tabular}

$\mathrm{Me}-\operatorname{median}(\min -\max )$

\section{Conclusions}

E-textbooks enter schools and universities, changing the educational methods and techniques in an irreversible way. This is caused not only by the technological advances that enable their development, but also by their pedagogical value, which is seen in their influence on the effectiveness of the education process. These interactive resources with non-linear study paths and different difficulty levels, contribute to the individualization of the learning process and constitute a convenient way of gaining knowledge and skills. Open access creates opportunities for better learning experiences for students living in non-urban areas. With their different functionalities, e-textbooks are capable of meeting the varied requirements of students nowadays, whose needs are difficult to satisfy by the traditional education systems. An increase in the interest in the implementation of etextbooks may result from an increase in staff competencies and an analysis of good practices. The authors' experience, supported by the research, indicates that an e-textbook is still confused with the electronic version of a traditional textbook. The analysis of the data collected during the research, which targeted medical university environments, has shown that the staff rarely develop academic e-textbooks. There are several reasons, the most important of which is the lack of adequate remuneration and IT competencies. According to the authors, it is necessary to continue the research 
on the use of e-textbooks in academic education and extend it by addressing the issue of their influence on the effectiveness and quality of the education process. The paper resulted from research conducted by the members of Poznan Association of Academic E-learning local group in the academic year 2017/2018. The local group meets at the Medical E-education Lab of the Department of Pathophysiology, Poznan University of Medical Sciences. Its members started collaborating in December 2015.

\section{R E F E R E N C E S}

Bates, M. L., Strother, E. A., Brunet, D. P., \& Gallo, J. R. (2012). Electronic textbooks as a professional resource after dental school. Journal of Dental Education, 76(5), 635-640.

Berezovskaya, I. P., \& Shipunova, O. D. (2015). Reverse side of multimedia pedagogics: clip thinking. Mediterranean Journal of Social Science, 6(6) S1, 277280. doi: $10.5901 /$ mjss.2015.v6n6s1p277

Bibliotech (2018). Subscription eTextbooks. Retrieved from https://bibliotech.edu cation

Ditmyer, M. M., Dye, J., Guirguis, N., Jamison, K., Moody, M., Mobley, C. C., \& Davenport, W. D. (2012). Electronic vs. traditional textbook use: dental students' perceptions and study habits. Journal of Dental Education, 76(6), 728-738.

Garcia, M. P., \& Serrano, J. A. (Eds.) (2009). Educational tools for Second Life: a handbook for educators in virtual worlds. Brussels, Belgium: MENON Network EEIG.

Harvey, C., Eshleman, K., Koo, K., Smith, K. G., Paradise, C. J., \& Campbell, A. M. (2016). Encouragement for Faculty to Implement Vision and Change. CBE-Life Sciences Education, 15(4). doi: 10.1187/cbe.16-03-0127

HCH (2018). Heartstone Community Hospital. Retrieved from https://www.heart stonecommunityhospital.com

Hołowiecki, M. (2014). Wykorzystanie e-learningu jako formy kształcenia zdalnego na publicznych uczelniach wyższych w Polsce. Lingua ac Communitas, 24, 185-206.

Imperial College of Science, Technology and Medicine, London (2017). Supporting education in virtual worlds with virtual learning environments - JISC (Second Life \& Moodle). Retrieved from https://www.imperial.ac.uk/medicine/ study/e-learning/second-life/

Jisc (2018). E-books for FE. Retrieved from https://www.jisc.ac.uk/e-books-for-fe

Kąkol, Z., \& Żukrowski, J. (2017). E-physics. Retrieved from http://home.agh.edu. $\mathrm{pl} / \sim$ kakol/efizyka/

Lorens, R. (2013). E-podręcznik w ramach projektu Cyfrowa Szkoła (E-book within the project 'Digital School'). E-mentor, 4(51), 39-43. 
Leszczyński, P., Charuta, A., Gotlib, J., Kołodziejczak, B., Roszak, M., \& Zacharuk, T. (2017). Distance Learning Methods in Continuing Education of Paramedics. Studies in Logic, Grammar and Rhetoric. Logical, Statistical and Computer Methods in Medicine, 51(64), 53-70. doi: 10.1515/slgr-20170033

Ministry of Science and Higher Education (2018). Studyfinder. Retrieved from http://wybierzstudia.nauka.gov.pl/pages/about/index

Mynbayeva, A., Sadvakassova, Z., \& Akshalova, B. (2018). Pedagogy of the Twenty-First Century: Innovative Teaching Methods. In O. Bernad Cavero \& N. Llevot-Calvet (Eds.), New Pedagogical Challenges in the 21st Century (pp. 3-20). IntechOpen. doi: 10.5772/intechopen.72341

Open Access (2018). The list of library resources under the open access license. Retrieved from http://www.imdik.pan.pl/pl/biblioteka/open-access

Radovic, M., Milosevic, D., Mitrovic, A., \& Blagojevic, M. (2015). Exploring virtual assignments in Sloodle Medical Course. In Proceedings of The Sixth International Conference on e-Learning (eLearning-2015) (pp. 131-136). Retrieved from http://econference.metropolitan.ac.rs/files/pdf/2015/20-Marija-Radov ic-Danijela-Milosevic-Marija-Blagojevic-Andjelija-Mitrovic-Exploring-virtua l-assignments-in-sloodle-medical-course.pdf

Ren-Kurc, A., Kołodziejczak, B., Roszak, M., \& Kowalewski, W. (2013). A new dimension of editorial competencies - ebook. In M. Dąbrowski \& M. Zając (Eds.), The role of e-education in the development of academic education (pp. 161-169). Warsaw: Foundation for the Promotion and Accreditation of Economic Education.

Rickes, P. C. (2016). Generations in flux: how gen $\mathrm{Z}$ will continue to transform higher education space. Planning for Higher Education, 44(4), 21-45.

Rockinson-Szapkiw, A. J., Courduff, J., Carter, K., \& Bennett, D. (2013). Electronic versus traditional print textbooks: A comparison study on the influence of university students' learning. Computers \& Education, 63, 259-266.

Sandholzer, M., Rurik, I., Deutsch, T., \& Frese, T. (2014). Medical students' expectations towards an implementation of a family medicine textbook as a comprehensive app in Germany. Journal of Medical Systems, 38(10): 125. doi: 10.1007/s10916-014-0125-y

Seid-Karbasi, P., Ye, X. C., Zhang, A. W., Gladish, N., Cheng, S. Y., Rothe, K., Pilsworth, J. A., et al. (2017). CuboCube: Student creation of a cancer genetics e-textbook using open-access software for social learning. Plos Biology, 15(3), e2001192. doi: 10.1371/journal.pbio.2001192

Sloodle (2012). Free and open source project which provides a range of tools for supporting learning and teaching to the virtual world. Retrieved from https://www.sloodle.org

Szulc, J. (2018). Personalization in e-learning. An overview of solutions. The Scientific Papers of Faculty of Electrical and Control Engineering Gdańsk University of Technology, 58, 81-84. 
Aldona Dutkiewicz et al.

Walat, W. (2013). Evolution of school books - from the printed to the electronic version. Education-Technology-Computer Science, 4(2), 168-178.

Wejnarski, A., Gajek Villebæk, P. A., \& Leszczyński, P. (2018). Prospective evaluation of interactive project of Emergency Medicine Exam with the use of multimedia computer devices. Critical Care Innovation, 1(1), 1-15. 